\title{
Personality Traits and Drug Usage among Addicts
}

\author{
Farhad Ghorban DordiNejad, Maryam Asbaghi Ghareh Shiran \\ Shahid Rajaee Teacher Training University
}

\begin{abstract}
This research has been performed to investigate the relationships between the personality traits and drug usage among the addicted society members. 200 people took part in the present investigation. They were selected in clusters at random from among addicted communities who referred to the centers for stopping addiction and answered Neo personality traits questionnaires and the questionnaire for drug usage withdrawal. Resulted data were analyzed using Pearson's correlation coefficient and simultaneous regression. The results of the research indicate that conscientiousness has the highest correlation $(P<0.01, r=-063)$, of course personality traits of extroversion $(P<0.01, r=-0.51)$, neurosis orientation $(P<0.01, \quad r=0.43)$, and compatibility $(P<0.01, r=-0.43)$ with the use of drugs, But openness to experience has no correlations with the drug usage. Also, the results of analyzing regression indicates that the differentials of extroversion, conscientiousness explain $(P<0.001) 0.56$ of variance of drug usage. According to the increase in the number of addicts, dangerous drugs and frequent returns among the addicts, identifying dangerous factors and critical prerequisites of identifying addiction decreases the range of its dangers.
\end{abstract}

\section{Introduction}

Personality traits have been defined as habitual patterns of behavior, thought, and emotion. [1] According to this perspective, traits are relatively stable over time, differ across individuals, and influence behavior. There are so many potential traits that could be used to describe personality. However, factor analysis as a statistical technique, has demonstrated that particular clusters of traits reliably correlate together. Based on this technique, Eysenck has suggested that personality is reducible to three major traits which contains the traits of extroversion, neuroticism, and psychoticism. [2] [3] Other researchers argue that more factors are needed to adequately describe human personality. [4] Many psychologists currently believe that five factors are sufficient. [5] [6]

The "Big Five" also referred to as the "FiveFactor Model" is five broad domains or dimensions of personality which have been scientifically discovered to define human personality at the highest level of organization [7]. These factors (dimensions) of personality are based upon empirical research. These five over-arching domains have been found to contain and subsume more-or-less all known personality traits within their five domains and to represent the basic structure behind all personality traits. The big five traits are also referred to as the "Five Factor Model" or FFM [6], and as the Global Factors of personality [8].

The personality traits are measurable and there are two main personality traits tests to measure the Big Five are the "Big Five Inventory" (BFI) and the IPIP (International Personality Item Pool) an abbreviated form is the "IPIP-NEO".

The Big Five factors and their constituent traits can be summarized as: 1) Openness to Experience/Intellect: It is a general appreciation for art, emotion, adventure, unusual ideas, imagination, curiosity, and variety of experience. People who are open to experience are intellectually curious, appreciative of art, and sensitive to beauty. They are more likely to hold unconventional beliefs. 2) Conscientiousness: It is a tendency to show selfdiscipline, act dutifully, and aim for achievement. The trait shows a preference for planned rather than spontaneous behavior. It influences the way in which we control, regulate, and direct our impulses. 3) Extroversion: It is characterized by positive emotions, urgency, and the tendency to seek out stimulation and the company of others. The trait is marked by pronounced engagement with the external world. Extroverts enjoy being with people, and are often perceived as full of energy. They tend to be enthusiastic, action-oriented individuals. In groups they like to talk, assert themselves, and draw attention to themselves. Introverts tend to seem quiet, low-key, deliberate, and less involved in the social world. Introverts simply need less stimulation than extroverts and more time alone. 4) Agreeableness: It is a tendency to be compassionate and cooperative rather than suspicious and antagonistic towards others. Agreeable individual's value is getting along with others. They are generally considerate, friendly, generous, helpful, and willing to compromise their interests with others. Agreeable people also have an optimistic view of human nature. They believe people are basically honest, decent, and 
trustworthy. In fact, agreeableness refers to a compliant, trusting, empathic, sympathetic, friendly and cooperative nature [9] [10] [11] 5. Neuroticism: It is the tendency to experience negative emotions, such as anger, anxiety, or depression. It is sometimes called emotional instability. In fact, "Neuroticism is the major factor of personality pathology" [12].

Man has exploited narcotics to cure diseases, relieve pain and reduce mental sufferings for thousands of years. However, the benefit of drug usage has exceeded the clinical and health borders and changed into a social-psychological problem. The increase in using narcotics during the last century has had increasing anxiety for all communities [13]. Therefore, the question confronting most psychologists, psychiatrists, social helpers, ... is: why only a special number suffer the misuse of the drugs and get dependent to it. Do specific personality traits distinguish between the addicts and the ordinary people? Are these attributes and characteristics resulted from the differences made by using narcotics for a long time or the person had had the features before becoming an addict [13]? Primary research about the attributes and personality features addicted individuals resulted that the dependence combined with aggression towards others, lack of emotional growth and ambivalence to those who have a role in the person's life, lowness of the failure tolerating threshold, guilt-feeling, derangement of sexual role are among those characteristics observed in the addicts. But the next researches indicated that the above mentioned features do not belong solely to the addicted people [14]. Brewer et al. [15] believe that addiction can be seen among all groups. Then it can be the result of addiction causing personality. They believe that the high psychotism and probably neurotism are not the special changes of the addicts, but have also been reported in other mental states. In their opinion, the specific personality seen in addicts is not the ground for addiction, but the consequences of long-term narcotics usage. On the other hand, Fisher et al.'s research [16] aiming at studying the personality traits making addiction susceptible, effective in return after cure studied 108 hospitalized addicts using 5 factor personality test. This analysis indicated that two personality traits namely high neurosis orientation and low conscientiousness have important roles in addiction and repeated returns after treatment.

According to other researches performed a great number of the patients having misuse or dependence on narcotics have an anti-society behavioral pattern. These behavioral patterns may cause the addicted individual not to surrender to psychological helps and deny all problems and try to changing the environment outside according to his/her requirements, and continue to use narcotics without any effort to quit it [17].
Kidorf et al.'s research [18] indicated that the addict's personality profile is effective in choosing and preference of the kind of narcotics. Also, in new ground finding of Kircaldy et al. the effects of personality on individual and social differentials were studied and considerable results were obtained about the relationship between personality structure and choosing the kind of drug (Quoted from [19]). The present research intends to study the relationship between the personality traits and drug usage regarding the contradictions found in the previous studies on personality traits and drug usage.

\section{Methodology}

The present research is descriptive and of the kind of correlation. 200 people were selected by simple random sampling from among the addicts who referred to quit to the centers of withdrawal either by themselves or through introduction. It should be mentioned that the age domain of these people was 17-73. All of them were men.

The NEO-FFI questionnaire was used to assess their personality traits. This questionnaire was in fact the abridged 240 question NEO-PI-R with 60 questions to evaluate the 5 personality types (namely neurosis orientation, extroversion, openness to experience, compatibility, and conscientiousness) which has been made by Costa and Mac Craw and is numbered on the basis of Lickert's 5-degree scale from fully opposed to fully agreed. Validity coefficient of retesting its scales after three months has been obtained from 83\% to 75\% [20], [21], [22]. Gaross Farshi, [10] has also reported the internal uniformity for each of the neurosis orientation, extroversion, openness to experience, compatibility, and conscientiousness factors $86 \%, 73 \%, 56 \%, 68 \%$, and $87 \%$ respectively. To measure drug usage, we used drug usage questionnaire containing 36 multiple questions with Lickert's scale. This questionnaire has been assembled by the cultural affairs and prevention deputy of the ministry of welfare. The validity of this questionnaire in different researches varied from $65 \%$ to $83 \%$. One of the main points of this questionnaire is that it reveals the severity of usage and addiction in the addict. Analysis of the data through Pearson's correlation coefficient and simultaneous regression analysis supported this.

\section{Findings of the Research}

Table 1 indicates that conscientiousness has the highest correlation $(\mathrm{P}<0.01, \mathrm{r}=-0.63)$ with drug usage, of course the personality traits extroversion $(\mathrm{P}<0.01, \mathrm{r}=-0.51)$, neurosim $(\mathrm{P}<0.01, \mathrm{r}=0.43)$ and compatibility $(\mathrm{P}<0.01, \mathrm{r}=-043)$ have a meaningful relation with drug usage, but openness to experience doesn't have such a relationship. 
Table 1. Correlation Matrix between Personality Traits and Vision towards Drug Usage

Neurosisism Extroversion openness compatibility conscientiousness usage

\begin{tabular}{|c|c|c|c|c|c|}
\hline Neurosism & & & & & \\
\hline Extroversion & 0.15 & & & & \\
\hline Openness & $0.24^{* *}$ & -0.09 & & & \\
\hline Compatibility & $0.40^{* *}$ & $0.39^{* *}$ & 0.07 & & \\
\hline Conscientiousness & $-0.22^{*}$ & $0.39^{* *}$ & -0.02 & $0.36^{* *}$ & \\
\hline drug usage & $0.43^{* *}$ & $-0.51^{* *}$ & -0.05 & $-0.43^{* *}$ & $-0.62^{* *}$ \\
\hline
\end{tabular}

$* *=\mathrm{P}>0.01$

$*=\mathrm{P}>0.05$

In order to explain and foretell the variance of drug usage through personality traits simultaneous regression has been used (See Table 2). Table 2.
Shortened simultaneous regression analysis of drug usage through personality traits and attitude towards drug usage.

Table 2. Shortened simultaneous regression analysis of drug usage through personality traits and attitude towards drug usage

\begin{tabular}{|c|c|c|c|c|c|}
\hline $\mathrm{B}$ & $\beta$ & $\mathrm{t}$ & $\mathrm{P}$ & $\mathrm{R}^{2}$ & $\mathrm{~F}$ \\
\hline $\begin{array}{ll}\text { Constant } & 142.18\end{array}$ & - & 5.51 & 0.001 & & \\
\hline $\begin{array}{c}\text { Extroversion }-1.29 \\
0.001\end{array}$ & -0.30 & 2.36 & 0.02 & 0.56 & 9.64 \\
\hline Conscientiousness -1.68 & -0.39 & -3.42 & 0.001 & & \\
\hline
\end{tabular}

According to the results of Table 2, only two differential of extroversion and conscientiousness explain 0.49 of the changes in drug usage $(\mathrm{P}<0.01$, $\mathrm{F}=9.64)$ in the addicts. That is to say that 0.49 of the variance and diffraction existing in the drug usage differential can be foretold through the differentials extroversion, conscientiousness, and attitude towards drug usage.

\section{Discussion and conclusion}

The present research was performed with the aim of determining the relationship between personality traits and drug usage.

On the basis of correlation matrix between NEO's personality traits with drug usage, all differentials except openness to experience have relationship with drug usage, among which conscientiousness has the highest (reverse) correlation approved by some research findings [14].

Regression equation of explaining drug usage through personality traits and attitude towards drug usage indicates that from among the differentials, only extroversion and conscientiousness have the ability of foretelling that this finding accords with Fisher et al. [16], [14], and [19]. In order to explain such a finding, it can be said that extroverts, because of their personality trait, prevent from the accumulation of problems inside themselves. On the contrary, the introverts accumulate them inside and follow strategies that consider the individual himself as the center of notice and addiction is a false solution under whose protection they pose themselves. This personality trait that is introversion is also satisfied and prevents the individuals from referring to different sources able to help one confront the difficulties. From the conscientiousness point of view the obliged person considers a series of norms necessary for himself, his family and surroundings and society. He regards it as his duty to be a fruitful person in the society and undertake a respectable role in it. He doesn't wish to be a burden for others in the community and escape from the responsibilities and duties put on his shoulders and throw them to others. Therefore, the reverse relationship between dutifulness and drug usage can be due to the effects of addiction on his physical, social, and emotional functions and interference in this function can be because of the negative influence of drug using in central nervous system that causes decrease in activity rate, having impulsive behaviors in job and social situations, following disorder in individual's activity in his work 
place, arrangement of his feelings and excitements, social behavior, etc.

Nowadays, regarding the dangerous nature of addiction and the high number of the addicts in society, difficulties, problems and family, individual, job, financial and social complications and its possible effects on other society members, identifying its risk factors and distinguished prerequisites can be helpful in cure and prevention discussions and preventing the its return.

\section{References}

[1] Saul Kassin, (2003). Psychology. USA: Prentice-Hall, Inc.

[2] Hans Eysenck, (1967). The biological basis of personality. Springfield, IL: Thomas.

[3] Hans Eysenck, (1991). Dimensions of personality: 16: 5 or 3? Criteria for a taxonomic paradigm. Personality and Individual Differences, 12, 773-790.

[4] Saucier, G., \& Goldberg, L. R. (1998). What is beyond the Big Five? Journal of Personality, 66, 495-524.

[5] McCrae, R. R., \& Costa, P. C., Jr. (1987). Validation of the five-factor model across instruments and observers. Journal of Personality and Social Psychology, 52, 81-90.

[6] Costa, P. T., \& McCrae, R. R. (1992). Four ways five factors are basic. Personality and Individual Differences, $13,653-665$.

[7] Goldberg, L. R. (1993). The structure of phenotypic personality traits. American Psychologist, 48, 26-3.

[8] Russell, M., \& Karol, D. (1994). Administrator's Manual 16PF (5th ed.). Champaign, IL: Institute for Personality and Ability Testing, Inc.

[9] Graziano WG, Tobin RM.Agreeableness: dimension of personality or social desirability artifact? Bergeman CS et al. Genetic and environmental effects on openness to experience, agreeableness, and conscientiousness: an adoption/twin study. J Pers. 1993 Jun; 61(2):159-79.PMID 8345444.

[10] J Pers. 2002 Oct; 70(5):695-727. PMID 12322857.

[11] Miller JL et al. Neuroticism and introversion: a risky combination for disordered eating among a non-clinical sample of undergraduate women. Eat Behav. 2006 Jan; 7(1):69-78. Epub 2005 Aug 1. PMID 16360625.

[12] Eysenck, H.J. \& Eysenck, S.B.G. (1969). Personality Structure and Measurement. London: Routledge.

[13] Heidari Pahlavan, Ahmad; Amir Zargar; Mohammad Ali Farhadi Nasab; Abdollah Mahjoob; Hossein (1382). Comparative Survey between Personality Traits of Drug Addicts and Non-addict Residents in Hamedan. Scientific Journal of Medical Science, Health and Clinical Services of Hamedan. Tenth year, No. 2, 55 - 62 .

[14] Bayat Mokhtari, Leila (1388), A Survey in Personality Traits and the Number of Times an Addict Quits. Quarterly of Addiction, No. 9, pp. 99 - 103.

[15] Breier J.I., Simos P.G., Zouridakis G., Papanicolaou A.C. (1998) Relative timing of neuronal activity in distinct temporal lobe areas during a recognition memory task for words. J. Clin. Exper. Neuropsychol. 20:782-790

[16] Fisher L. Elyas; J. Rinse B. (1998) Foretelling Drug Abuse Returnin Relation with Personality. Translated by Salehi, Mansour (1379), Journal of Iran Psychiatrists Club, Second year, No. 7.

[17] Sadock BJ\& Sadock VA (2003) Mood disorders.Kaplan\&Sadock's Synopsis of Psychiatry; 2,15: 527-578

[18] Kidorf, M., Disney, E. R., King, V. L., Neufeld, K., Beilenson, P. L., \& Brooner, R. K. (2004). Prevalence of psychiatric and substance use disorders in opioid abusers in a community syringe exchange program. Drug and Alcohol Dependence, 74, 115-122.

[19] Koushki, Shirin (1385), Surveying the Relationships between Mental Disorders and Methods of Confrontion Drug Abuse among Addicts. Doctoral Dissertation of Specialty; Islamic Azad University.

[20] Costa, P. T., Jr., \& McCrae, R. R. (1992). NEO PI-R professional manual. Odessa, FL: Psychological Assessment Resources, Inc.

[21] Costa P.T., Jr. \& TA Widiger (Eds.), Personality disorders and the Five-Factor ... Epstein, S., \& Meier, $P$. (1989).

[22] Garousi Farshi. M. T, Personality Evaluation.Tabriz: Jame Pazhoh. 1380. 